\title{
Influence of Soil Structure on the Mechanical Response of Soft Soil
}

\author{
Bin Bin XU \\ Tianjin Port Engineering Institute, Key Lab. of Geotechnical Engineering of Tianjin, Key Lab. of Geotechnical Engineering, Ministry of \\ Communication, Tianjin, 300222, China
}

\begin{abstract}
Usually the natural sedimentary soils possess structure more or less, which makes their mechanical response much different from the fully remolded soils. In this paper, the influence of soil structure on the mechanical response such as compressibility, shear, permeability is literately reviewed. It is found that the compressibility and consolidation behavior of structured and remolded soils can be divided clearly before or after the structural yield stress. The stress-strain relationship can be divided into two segments before and after the structural yield stress. Before the yield stress, the curve is elevating and after the yield stress the curve is decreasing. The increasing rate of pore water pressure increases after the soil reached yield stress.
\end{abstract}

\section{Background}

As the development of the economic, many large engineering such as port, breakwater, storage tank, airport, railway and express highway have been built on the natural structured ground. If there is no comprehensive and deep acquaintance to the natural sedimentary clay, it is impossible to forecast the mechanical response. For example, the Kansai international airport is built by the land reclamation in the sea to form an artificial island. There has been over $12 \mathrm{~m}$ settlement since its operation, which gives significant influence on the following maintenance. Now in the Hongkong-Zhuhai-Macau bridge engineering, there are also two artificial islands in the sea to connect the bridge passage and the immersed tube tunnel, its post-construction settlement is bound to be very important for the engineers.

As the development of boring technology, the recognition to the natural structured soil is more and more thoroughly. Due to the structure, the mechanical response of natural soil is quite different from the corresponding fully remolded soil. For the geo-materials, the structure displays as the shape of soil particles and void ratio, the pattern of arrangement, the mechanical action among particles. When the structured soil is loaded, its structure varies accordingly, which results in the corresponding variation of physical and mechanical properties of soft soil. From the aspects of practical engineering, there may be two problems. If we ignore the structure of natural soil and only predict its response based on the fully remolded samples or disturbed samples, the stiffness and strength of natural soils may be underestimated so that the design may be relatively safe.
On the other side, if we only recognize the low compressibility of natural soil under low stress level but neglect the significant compressibility when the stress is over the yield stress, the stiffness of natural soil would be overestimated, which may threaten the safety of the construction. In this paper, the influence of soil structure on the mechanical response of ground is reviewed in detail to help the engineer to comprehend its importance.

\section{Conception of Soil Structure}

Leroueil et al. [1] pointed that the structure of soil is the expression of sedimentary, load experience. For this view, any soil at any state should be more or less structured. Also he proposed four different state of soil corresponding to the structures: undisturbed state, destructured state, remolded state, resedimented state. The undisturbed state is the natural sedimentary state which is a complex proceeding. The destructured state corresponds to the variation of structure due to volumetrical or shearing deformation. The remolded state means that the soil is loaded enough so that the structure is fully destroyed. The resedimented state is the slurry state of remolded soil and it is depended on the mineral constituent, particle size, sedimentary rate and other environment.

The remolded state can reflect the mineral constituent and sedimentary environment of natural soil. The variation from the undisturbed state to the destructured state until the remolded state represents the gradual loss of structure. The remolded soil represents the state that the combination among the soil particles is destroyed and the large void is eliminated, where the soil is an even configuration at the macroscopic view. Therefore, the mechanical properties of remolded soil are the most

* Corresponding author: xubinbin@tpei.com.cn 
essential characteristics. Leroueil and Vaughan [2] defined the concept of structured permitted space, as shown in Figure 1, to demonstrate the relationship of three states. The influence of soil structure has been recognized in the early stage. Leroueil et al. [2, 3] proposed the concept of structure by comparing the natural soil and soft rock. The mechanical response of nature soil and remolded soil can be distinguished when considering the structure. Therefore, the structure of soil is as important as the initial void ratio, stress history to determine the mechanical property.

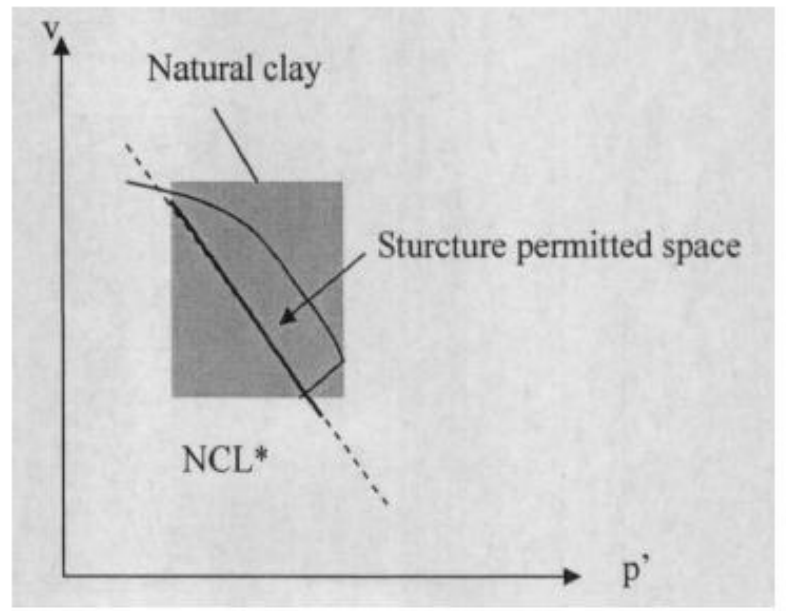

Figure 1 Sketch of structured permitted space of nature clay compression curve of the undisturbed soil. The stress corresponding to the turning point on the compression curve is usually called structural yield stress or apparent pre-consolidation pressure, which is usually larger than the overburden effective stress. When the current stress is

\subsection{Influence on Compressibility}

The compressibility of soil is always the highlight in the research and it is the foundation for solving many geotechnical engineering problems, especially for the settlement. Mesri [4], Zhang [5], Zhou [6], Wang [7] and other scholars have researched the structure of soil in different areas including Mexico, Zhanjiang, Hangzhou, Wenzhou etc. The research results show that the compression curve of the structured soil is quite different from that of the remolded soil. Because of the soil structure, there is obvious turning point in the smaller than the structural yield stress, the compressibility of the structured soil is relatively low. If the current stress is larger than the structural yield stress, the compressibility is much high. Finally, the compression curve of the structured soil is gradually close to the compression curve of the remolded soil as the stress increases. Usually the void ratio of the structure soil is larger than that of the remolded soil for the same stress level. 


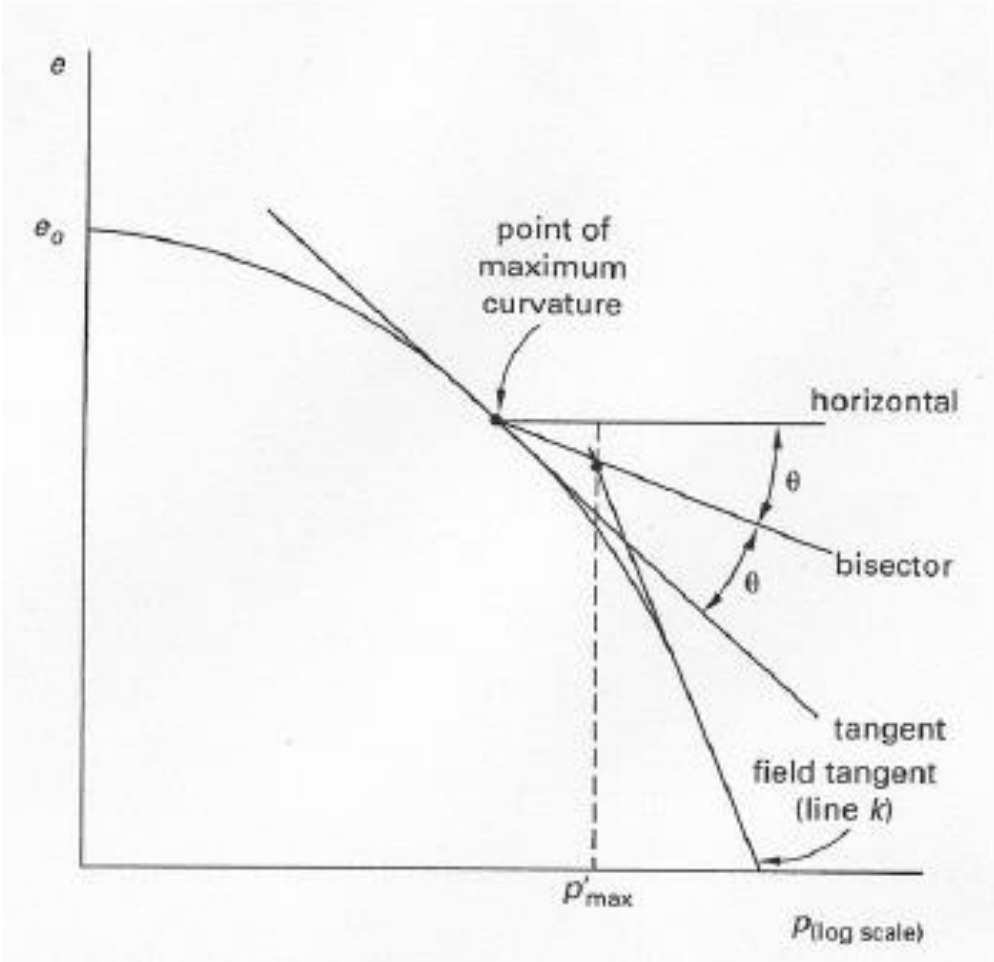

Figure 2 Casagrande's method to determine pre-consolidation pressure

Usually the response of undisturbed soil is used to represent the response of the in-situ natural soil considering that the in-situ soil specimen is different to obtain. However, the undisturbed soil in the laboratory is more or less disturbed such as the unloading influence of taking specimen, the mechanical disturbance of core sampler or the disturbance during the sampling, which may make the compression curve of undisturbed specimen quite different from the in-situ compression curve. Many scholars have researched the method to predict the in-situ compression curve according to the compression curve of the undisturbed specimen. The most common method to determine the pre-consolidation pressure is the Casagrande's method [8], as shown in figure 2. Figures 3 and 4 give Schmertmann and Nagaraj methods [9-10] to determine the in-situ compression curve based on the undisturbed compression curve. Detailed explanation and operation can be found in relative references.

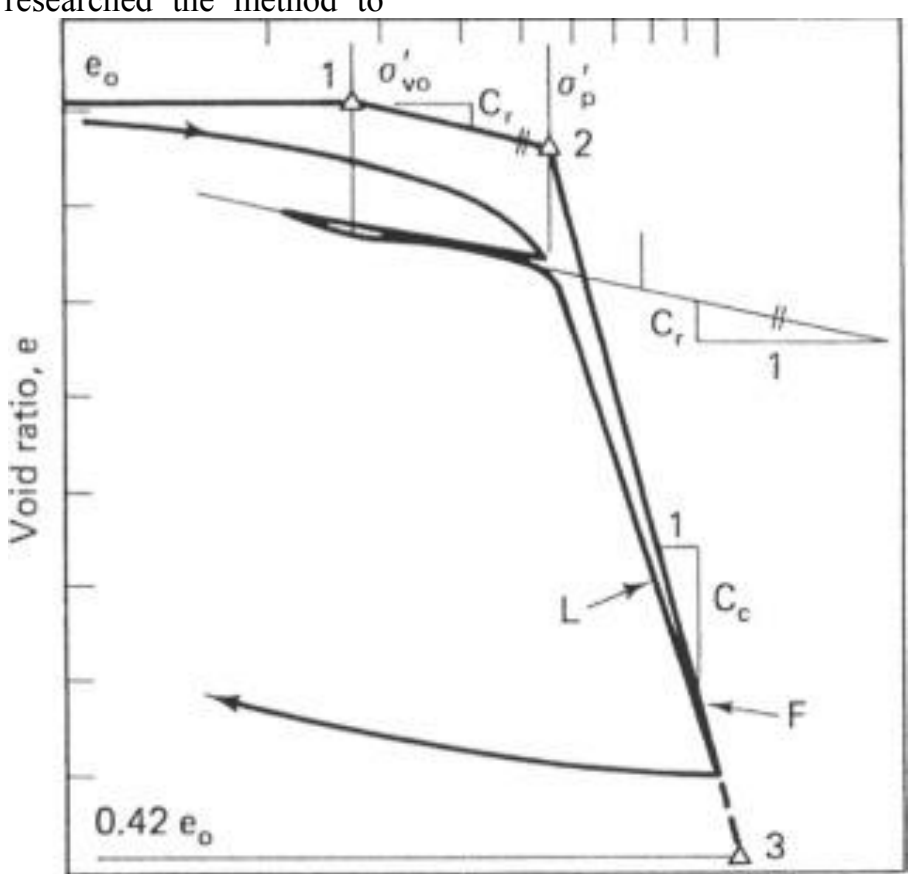

Effective consolidation stress, $\sigma_{\mathrm{ve}}^{\prime}$ (log scale)

Figure 3 Schmertmann method to determine in-situ compression curve 


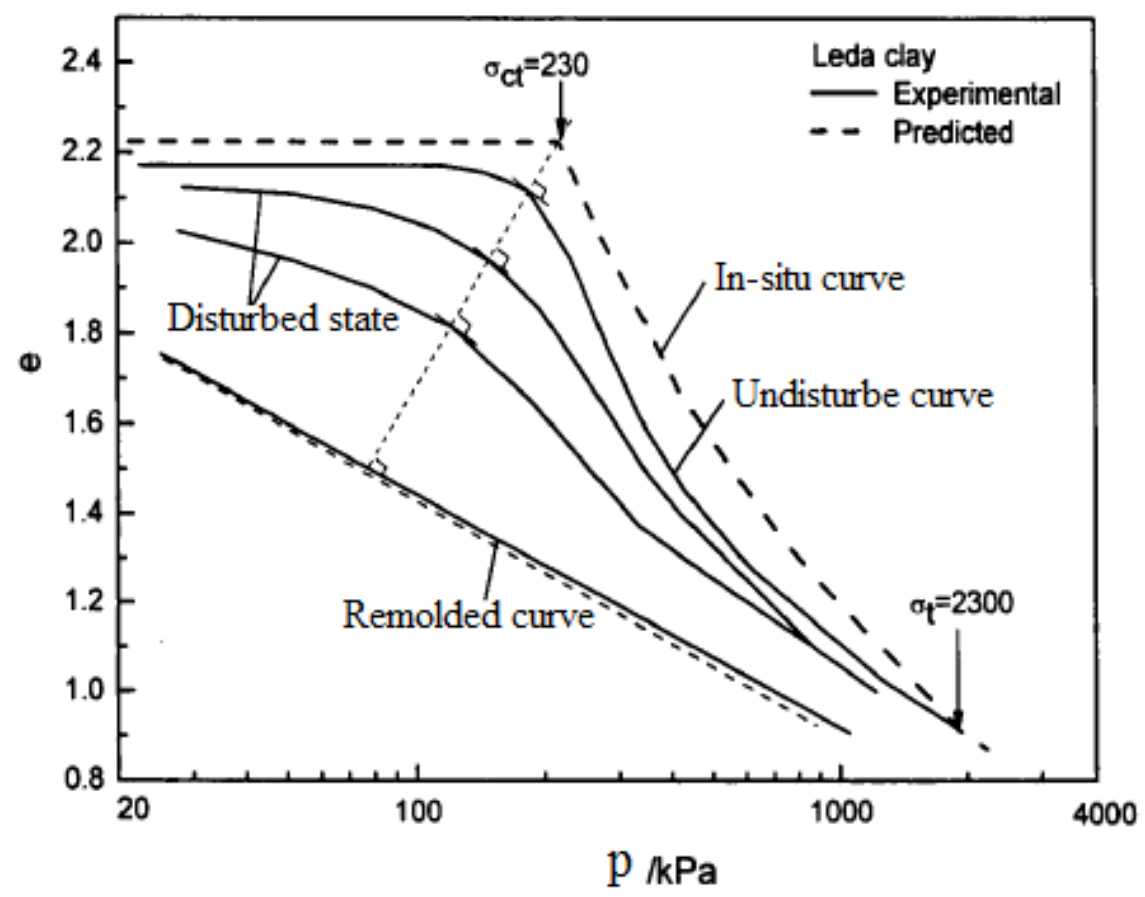

Figure 4 Nagaraj method to determine in-situ compression curve lower than the structural yield stress the consolidation coefficient of structured soil is larger than that of the remolded soil. When the current stress is larger than the

\subsection{Influence on the Compression Index and} Secondary Consolidation Coefficient

Shen [11] believed that the soil structure would influence the consolidation coefficient. When the current stress is structural yield stress, the consolidation coefficient becomes close, as shown in figures 5 and 6 .

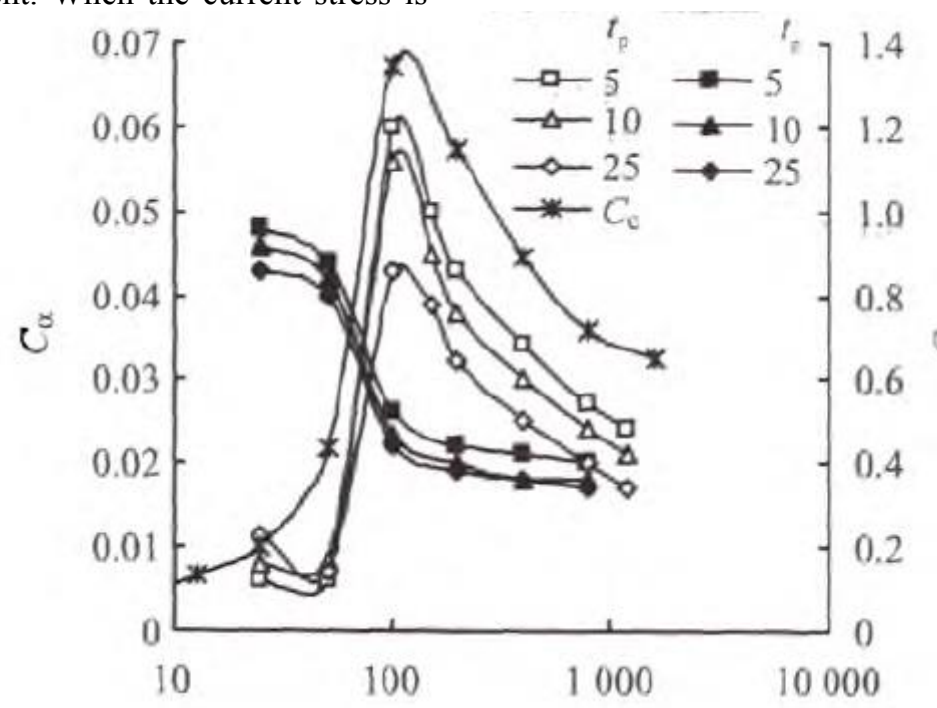

Figure 5 Relationship between compression index, consolidation coefficient and stress in Tianjin 


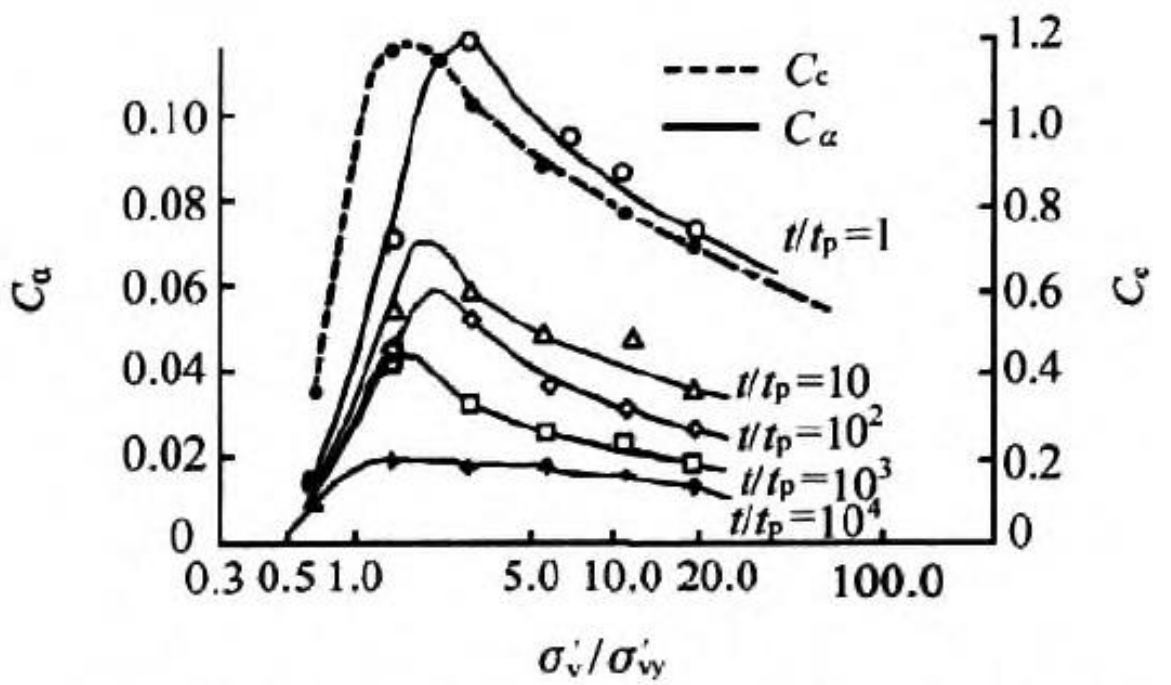

Figure 6 Relationship between compression index, consolidation coefficient and stress in Osaka

\subsection{Influence on Stress-strain Relationship}

In the triaxial consolidation drained compression test, for the structured natural clay the stress-strain relationship shows strain softening behavior when the consolidation stress is lower than the structural yield stress. When the consolidation stress is larger than the structural yield stress the stress-strain curve presents strain hardening behavior. The triaxial undrained compression tests of typical structural clay also show that the stress-strain relationship can be divided into two segments before and after the structural yield stress. Before the yield stress, the curve is elevating and after the yield stress the curve is decreasing. If the structured soil is disturbed, the structural strength decreases and peak strength also decreases, which means that the existence of structure can enlarge the stiffness of the soil. In the initial stage, the stress-strain relationship is under elastic state and then the percentage of plastic increases. When it reaches the peak strength, the soil structure is destroyed significantly so that the deformation increases greatly.

\subsection{Influence on Pore Pressure}

$\mathrm{Li}$ [12] found that in the undrained shear test the relationship between pore water pressure and structural yield stress differs with the variation of consolidation stress, and sometimes the Skempton coefficient is larger than 1. Lei [13] and Fang [14] investigated the undrained shear behavior of marine soft clay in Tianjin and it is found that after the soil reached yield stress the increasing rate of pore water pressure increases which proved that the pore water increases after the structural yield stress.

\section{Conclusion}

The influence of soil structure on the mechanical behavior has been reviewed literately and the conclusions are as follows:

1) There is obvious turning point in the compression curve of the undisturbed soil and before or after the turning point the compressibility of structured soil is quite different.

2) When the current stress is lower than the structural yield stress the consolidation coefficient of structured soil is larger than that of the remolded soil, after which the behavior becomes close.

3) The stress-strain relationship can be divided into two segments before and after the structural yield stress. Before the yield stress, the curve is elevating and after the yield stress the curve is decreasing.

4) The increasing rate of pore water pressure increases after the soil reached yield stress.

\section{Acknowledgement}

This work is supported by the Natural Science Foundation of Tianjin(16JCZDJC38800).

\section{References}

1. [1] S. Leroueil, F. Tavenas, J. Locat, Discussion on: Correlations between index tests and the properties of remoulded clays - Carrier W.D and Beckman J.F. [J]. Geotechnique, 35(2), (1985), p.223-226.

2. S. Leroueil, P.R. Vaughan, The general and congruent effects of structure in natural soils and weak rocks [J]. Geotechnique, 40(3): (1990), 467-488.

3. S. Leroueil, Compressibility of clays: Fundamental and practical aspects - closure $[\mathrm{J}]$. Journal of Geotechnical and Geoenvironmental Engineering, 123(9): p. 895-897.

4. Mesri G., Roskhsar A., Bohor B.F., Composition and compressibility of typical samples of Mexico City clay. Geotechnique, 25(3): (1975), p.527-554.

5. C. $\mathrm{H}$ Zhang. Geotechnical properties of two structural soils. [J] Hydro-Science and Engineering, 4, (1983) 65-71.

6. J. A. Zhou, X. N. Gong. Experimental study on soft clay structure property $[\mathrm{J}]$. Industrial Construction, 32(3), (2002), p.35-37. 
7. L. Z. Wang et al. Study on compressibility of structured soft soil $[\mathrm{J}]$. Chinese Journal of Geotechnical Engineering, 4: (2004), p.46-53.

8. Casagrande A., The structure of clay and its importance in foundation engineering $[\mathrm{J}]$. J. Boston Soc. Civ. Engrs., 19(4): 168-209.

9. Schmertmann J.H. The undisturbed consolidation behavior of clay. Transaction of ASCE, 120(2): 1201-1226, 1955.

10. Nagarj T.S., et al. Analysis of compressibility of sensitive soils. Journal of Geotechnical Engineering, ASCE, 116(1): 105-118, 1990.

11. Z. J. Shen, An elasto-plastic damage model for cemented clay [J]. Journal of Geotechnical Engineering, 15(3): (1993), p.21-28. Chinese

12. Li Z.Q. Mechanical properties of underconsolidated soil with structural strength $[\mathrm{J}]$. Journal of Geotechnical Engineering, 4(1): (1982), p.34-45. Chinese

13. LeiHuayang - Experimental studyon the structuralmodel of marine soft soil and its application to foundation pit excavation[D]. Changchun: Jilin University, 2001.

14. Fang H.G. et al. Structural strength of tianjin marine sofi soil and its influence on mechanical property [J]. Journal of Jilin University (earth science edition), 32(1), (2002), p. 73-76. 